\title{
КОГНИТИВНЫЕ КОМПОНЕНТЫ ТВОРЧЕСКОГО ПРОЦЕССА В КОНФЛИКТЕ СПОРТСМЕНОВ
}

\author{
(C) Кашапов М.М., Воскресенский А.М.
}

\author{
Кафедра педагогики и педагогической психологии \\ Ярославского государственного университета им. П.Г. Демидова, Ярославль \\ E-mail: voskresensky309@mail.ru
}

\begin{abstract}
Статья посвящена описанию когнитивных компонентов творческого процесса в конфликте спортсменов. Впервые установлена взаимосвязь творческого мышления спортсменов и выбора ими оптимального типа реагирования в конфликте, а также выявлена специфика взаимодействия творческих способностей спортсмена и его конфликтной компетентности. Обоснованы психологические механизмы конфликтов, возникающих в спортивной команде и негативно сказывающихся на психологическом состоянии спортсменов. Показано, каким образом данные состояния влияют на результат выступлений спортсменов. Рассмотрены причины возникновения конфликтов в спортивной среде, а также стратегии поведения в конфликте и связи этих стратегий с индивидуальными особенностями спортсменов. Установлены личностные особенности спортсменов, связанные с типом реагирования и стратегиями поведения в конфликте.
\end{abstract}

Ключевые слова: конфликт, креативность, спорт, конфликтная компетентность, стратегии поведения.

\section{COGNITIVE FEATURES OF THE CREATIVE PROCESS IN A CONFLICT OF ATHLETES}

Kashapov M.M., Voskresensky A.M.

Department of Pedagogics and Pedagogical Psychology of P.G. Demidov Yaroslavl State University, Yaroslavl

The article describes the cognitive components of the creative process in a conflict of athletes. The interrelation of creative thinking of athletes and their choice of an optimal response to the conflict was first revealed as well as the specific interaction between the creative abilities of an athlete and his conflict competence. The psychological mechanisms of conflicts that might arise in an athletic team and have a negative impact on the psychological state of athletes were established. It was shown how these states influence the result of athletic performances. In the article we considered the reasons of conflict in sport milieu and behavior strategies in a conflict and interralations between these strategies and individual characteristics of athletes. The personal traits of athletes related to the type of response and behavior strategies in a conflict were revealed.

Keywords: conflict, creativity, sports, conflict competence, the behavior strategy.

Особую роль в разрешении конфликтов играет творчество. Рассмотрение творческого мышления как ресурса конфликтной компетентности профессионала в контексте разрешения конфликта является наиболее перспективным и малоразработанным направлением в современной конфликтологии. Творческое отношение к конфликту предполагает ориентацию на поиск новых решений. Такой поиск осуществляется благодаря умению выходить за привычные, традиционные схемы и способы мышления [12].

Психологическая основа обучения творческому мышлению как средству повышения конфликтной компетентности профессионала включает в себя, во-первых, знание психологической природы творческого мышления профессионала; во-вторых, выделение надситуативного мышления как ведущего качества в структуре творческого мышления профессионала; в-третьих, рассмотрение надситуативного мышления в контексте повышения конфликтной компетентности профессионала [4].

Анализ состояния проблемы свидетельствует о том, что, несмотря на определенный уровень ее теоретической и практической разработанности, по-прежнему сохраняет свою актуальность вопрос о месте творчества в конфликтной компетентности. В современной социальной психологии отсутствует единый исследовательский подход к трактовке понятия «конфликтная компетентность» и определению ее структурных компонентов, а также роли творчества в функционировании данной компетентности.

Творческое отношение к конфликту предполагает рассмотрение его как увлекательной проблемы, развивающей творческой задачи, требующей своего эффективного и красивого разрешения. Принимая конфликт как вызов, источник внутреннего роста, предвкушая высшее наслаждение от его успешного разрешения и самоусиления, творческая личность не только рассматривает его как нечто неизбежное и должное, но и сама сознательно ищет и разрешает глубинные противоречия действительности, тем самым приближая себя, других и обстоятельства к идеалу [14].

Творческий подход к конфликту всегда подразумевает стремление выявить нераскрытые возможности всех структурных компонентов конфликтной ситуации, извлечь из него урок, 
пользу, выгоду, умение сделать выводы, чтобы стать совершеннее, глубже и сильнее [6].

Целостный, творческий подход к конфликту предполагает управление своей активностью, сознательное направление ее в разные содержательные русла. В самом начале конфликта необходимо, утверждают Ф.М. Бородкин и Н.М. Коряк, выделить те стороны ситуации, подвергающиеся нашему влиянию, а также те, которым можно позволить «вызревать» самостоятельно. Одновременно необходимо внимательно следить за развитием конфликта и определять, когда необходимо ждать, когда подготавливать необходимые события, а когда решительно действовать [2].

Творческое отношение к конфликту, к оппоненту и к самому себе носит многоуровневый, иерархический характер и включает аксиологический, когнитивный, эмоциональный и поведенческий компоненты, которые реализуются с помощью соответствующих реципрокных пар механизмов творчества. М.М. Кашапов и Ю.В. Скворцова отмечают, что творческое преодоление проблемных ситуаций требует понимания личностью их реальной сложности или имеющихся затруднений в своих интеллектуальных навыках [11]. Следовательно, деятельность, связанная с анализом возникшей проблемы, принятием во внимание условий, образующих конфликтную ситуацию, планированием ее решения, контролем и оценкой себя в ходе решения конфликта, является по своему содержанию творческой.

В последнее время спорт стал социально значимым явлением, и все глубже проникает в жизнь людей. Спорт - неотъемлемый компонент жизни общества. Поэтому спортивной деятельности уделяется все больше внимания во всех науках.

С возрастанием роли спорта в жизни общества увеличивается число конфликтов в спортивной среде. С одной стороны, это и не удивительно, ведь спорт сам по себе представляет соревновательную среду, где есть как минимум две конфликтующие стороны. С другой стороны, конфликты, возникающие в спортивной среде, негативно сказываются на психологическом состоянии спортсменов, что влияет на результат их выступлений.

Успешные выступления спортсменов во многом зависят от благоприятных взаимоотношений и психологической совместимости в коллективе.

Социальный конфликт, будучи одним из наиболее ярких проявлений противоречия, сам внутренне противоречив, выполняя не только деструктивную, но и конструктивную функцию. При выяснении роли конфликта принципиально важен конкретный подход. Один и тот же конфликт может быть деструктивным в одном отно- шении и конструктивным в другом, играть негативную роль на одном этапе развития, в одних конкретных обстоятельствах и позитивную - на другом этапе, в другой конкретной ситуации.

Спорт можно рассматривать как социальное образование, которое развивается благодаря конфликту и стимулируется им. Конфликт, который возник в спортивной команде, может способствовать ее сплочению и восстановлению внутреннего единства. Сторонники теории конфликтов утверждают, что внутренние конфликты, затрагивающие только цели, ценности и интересы, которые не противоречат принятым основам внутригрупповых отношений, как правило, носят функционально позитивный характер.

Стоит отметить, что исход конфликта зависит от того, какая это группа и от того, в какой социальной системе она находится. В данном случае нас интересует спортивная система, но она тоже внутри разделяется на несколько подсистем, например, спорт высших достижений и любительский спорт. В каждой из этих сфер конфликты будут протекать по-разному. В условиях спортивной системы конфликт может перестать быть актуальным, если команда добивается определенной цели, например, победы в соревновании.

Кроме этого, имеют место внешние конфликты, когда конфликтные отношения возникают между группами. Внутри таких групп атмосфера в этом случае обычно улучшается, так как им необходимо общими усилиями противостоять соперничающей стороне.

Современный спорт предъявляет высокие требования к физическим и психическим возможностям человека. Тренировочный, соревновательный и релаксационный процесс нередко сопровождается возникновением конфликтных ситуаций, переходящих либо в непосредственное, открытое, конфликтное взаимодействие, либо в скрытый или внутриличностпый конфликт [3].

Возникающие конфликты в сочетании с монотонностью тренировочного процесса и наличием неблагоприятных предсоревновательных состояний приводят к невротическим реакциям, нарушению системы межличностных отношений, в целом снижая эффективность спортивной деятельности [13].

Цель работы - исследование взаимосвязи творческого мышления и конфликтной компетентности в разрешении конфликтов спортсменами.

Задачи:

- установить взаимосвязь творческого мышления спортсменов и выбор ими оптимального типа реагирования в конфликте; 
- выявить специфику взаимодействия творческих способностей спортсмена и его конфликтной компетентности.

\section{МАТЕРИАЛЫ И МЕТОДЫ ИССЛЕДОВАНИЯ}

Эмпирическое исследование проводилось на выборке из 180 человек: 82 студента и 98 спортсменов (из них 28 борцов, 25 игроков молодежного футбольного клуба «Шинник», 24 игрока молодежного хоккейного клуба «Локо», а также 21 игрок любительского хоккейного клуба «Сатурн».

В своем исследовании мы использовали методики: опросник «Конфликтная компетентность» (В.А. Горшкова, М.В. Башкин, А.М. Воскресенский), тест «Креативность» (Н.Ф. Вишнякова), «Опросник способностей творческой личности» (О.А. Шляпникова, М.М. Кашапов), методика диагностики типа реагирования в конфликте (М.М. Кашапов, Т.Г. Киселева) [5, 7, 14].

В ходе исследования нами был проведен анализ различий трех групп по F-критерию Фишера (различие дисперсий) и t-критерию Стьюдента (различие средних). t-критерий Стьюдента справедлив при предположении о примерном равенстве дисперсий в группах.

\section{РЕЗУЛЬТАТЫ ИССЛЕДОВАНИЯ И ИХ ОБСУЖДЕНИЕ}

Все испытуемые были разделены на две группы - спортсмены и студенты. В свою очередь спортсмены были разделены на тех, кто участвует в командных видах спорта и индивидуальных, а так же на спортсменов-профессионалов и спортсменов-любителей. Отличие спортсменовпрофессионалов от спортсменов-любителей заключается в том, что для первых спорт является ведущей деятельностью, а также профессией, а для спортсменов-любителей спорт является второстепенным видом деятельности. Спортсменыпрофессионалы постоянно втянуты в тренировочный и соревновательный процесс, а любители периодически занимаются спортом.

Творческое мышление спортсменов влияет на выбор оптимального типа реагирования в конфликте. Полученные данные свидетельствуют, что спортсмены, обладающие творческим мышлением, склонны к поиску оптимального решения в конфликте, которое сможет удовлетворить обе стороны.

Установлено, что общий уровень творческих способностей взаимодействует с компонентами конфликтной компетентности спортсменов. Выявлена взаимосвязь между уровнем творческих способностей и когнитивным, эмоциональным и волевым компонентами конфликтной компетентности спортсменов. Данная взаимосвязь подтверждает утверждение, что творческая личность анализирует возникающие проблемы, принимает во внимание условия, образующие конфликтную ситуацию, планирует решение конфликта, а также адекватно оценивает себя в ходе решения конфликтной ситуации.

Полученные данные свидетельствуют о том, что творческий подход спортсменов к решению конфликтных ситуаций способствует управлению своим эмоциональным состоянием во время конфликта, а также контролю над собой. В ходе исследования были выявлены различия между спортсменами-профессионалами и спортсменамилюбителями в когнитивном компоненте конфликтной компетентности, творческом отношении к профессии и любознательности. Возможно, это связанно с тем, что спектр применения знаний о конфликтах и способах применения их на практике шире у спортсменов-любителей, чем у профессионалов, так как применяются они не только в спорте, но и профессиональной деятельности.

Творческое отношение к профессии ярче выражено у спортсменов-профессионалов (различия на уровне значимости $\mathrm{p}<0,001)$. Любители могут реализовывать свой творческий потенциал не только в профессии, но и в занятиях спортом, в то время как спортсмены-профессионалы реализуют свой творческий потенциал в профессии. Кроме творческого отношения к профессии у профессионалов чаще проявляется любознательность (различия на уровне значимости $\mathrm{p}<0,05)$. Любители могут реализовывать свой творческий потенциал не только в профессии, но и в занятиях спортом, в то время как спортсмены-профессионалы реализуют свой творческий потенциал в профессии.

Выявлены различия между спортсменами и студентами, не занимающимися спортом. Анализ достоверности различий показал различие в уровне способностей творческой личности (различия на уровне значимости $\mathrm{p}<0,05)$. У студентов уровень творческих способностей выше, чем у спортсменов. Учитывая, что показателями креативности можно считать беглость (количество порожденных идей), гибкость (их многообразие), оригинальность (редкость, нетривиальность решений), степень разработанности, детализации решений, то противоречивыми выглядят показатели по шкале оригинальность. У спортсменов ярче выражены любознательность и оригинальность (различия на уровне значимости $\mathrm{p}<0,001$ ). На наш взгляд это связанно с родом деятельности. Спортсмены много времени проводят на тренировках, поэтому для них характерен живой интерес в свободное время ко всему тому, что может обогатить жизненный опыт, дать новые впе- 
чатления, в то время как характер деятельности студентов и так предполагает получение новых знаний. Так же характер деятельности влияет и на оригинальность. Спортсменам для достижения лучшего результата или победы над соперником нужно привносить в свою деятельность что-то новое, все время совершенствоваться, в то время как задача студента в учебной деятельности сводится к приобретению знаний зачастую без проявления творческих способностей.

У спортсменов выше показатели по шкале «эмоциональность, эмпатия» (различия на уровне значимости $\mathrm{p}<0,001)$. Эмпатия - способность ощущать эмоции другого, ставить себя на место другого человека, способность к сопереживанию, сочувствию, проникновению в его субъективный мир. Несмотря на соревновательный характер деятельности спортсменов, они сталкиваются со схожими проблемами, что помогает им сопереживать другим участникам соревнований, с пониманием относиться к их трудностям. Зачастую многие спортсмены являются друзьями, несмотря на то что в то же время являются и соперниками.

Спортсмены и студенты различаются и по типу реагирования в конфликте. У студентов чаще преобладает в ситуации конфликта стратегия агрессивного поведения (различия на уровне значимости $\mathrm{p}<0,05)$, в то время как спортсмены чаще ориентированы на поиск оптимального решения конфликта (различия на уровне значимости $\mathrm{p}<0,001)$. Спортсмены привыкают работать в команде, несмотря на то, каким видом спорта занимаются - индивидуальным или командным. Поэтому для достижения высоких результатов им нужно находить оптимальные решения, будь то напарник по команде или тренер.

Мы нашли отличия между спортсменами и студентами в мотивационном компоненте конфликтной компетентности (различия на уровне значимости $\mathrm{p}<0,01)$. М.В. Башкин и М.М. Кашапов понимают под мотивационным компонентом конфликтной компетентности состояние внутренних побуждающих сил личности, которые благоприятствуют оптимальному поведению в конфликте. У студентов уровень мотивационного компонента выше, чем у спортсменов. Конфликтная компетентность предполагает, по их мнению, доминирование в поведении личности мотивации стремления к успеху, способствующей конструктивному разрешению конфликта [7].

Отличия видны и в эмоциональном компоненте конфликтной компетенции, который ярче выражен у студентов (различия на уровне значимости $\mathrm{p}<0,01)$. Под эмоциональным компонентом данные авторы понимают способность личности управлять своим эмоциональным состоянием в конфликтных, а также предконфликтных ситуа- циях, а также умение открыто выражать свои эмоции без оскорбления оппонента [7]. На наш взгляд, данные различия определяются характером деятельности. Соревновательный процесс, так же как и тренировочный, сопряжен с высокими нагрузками и большим эмоциональным напряжением, что и откладывает отпечаток на поведение спортсменов. Стоит отметить, что эти данные вступают в противоречия с данными, полученными по шкале «эмоциональность, эмпатия».

Анализ и обобщение эмпирических результатов позволяет сделать следующие выводы:

1. Творческое мышление спортсменов влияет на выбор оптимального типа реагирования в конфликте. Полученные данные свидетельствуют о том, что спортсмены, обладающие творческим мышлением, склонны к поиску оптимального решения в конфликте, которое сможет удовлетворить обе стороны.

2. Общий уровень творческих способностей влияет на компоненты конфликтной компетентности спортсменов. Обнаружены взаимосвязи между уровнем творческих способностей и когнитивным, эмоциональным и волевым компонентами конфликтной компетентности спортсменов.

3. Выявлены различия между спортсменамипрофессионалами и спортсменами-любителями в когнитивном компоненте конфликтной компетентности, творческом отношении к профессии и любознательности. Любители могут реализовывать свой творческий потенциал не только в профессии, но и в занятиях спортом, в то время как спортсмены-профессионалы реализуют свой творческий потенциал в профессии.

4. Спортсмены и студенты различаются по типу реагирования в конфликте. У студентов чаще преобладает в ситуации конфликта стратегия агрессивного поведения (различия на уровне значимости $\mathrm{p}<0,05)$, в то время как спортсмены в большей степени ориентированы на поиск оптимального решения конфликта (различия на уровне значимости $\mathrm{p}<0,001)$. Спортсмены привыкают работать в команде, несмотря на то, каким видом спорта занимаются - индивидуальным или командным. Поэтому для достижения высоких результатов они стремятся находить оптимальные решения, будь то напарник по команде или тренер.

Работа выполнена при финансовой поддержке РФФИ (Проект № 16-06-00196а).

\section{ЛИТЕРАТУРА}

1. Анцупов А.Я., Шипилов А.И. Проблема конфликта: аналитический обзор, междисциплинарный биб- 
лиографический указатель. - М. : ГАВС, 1992. $236 \mathrm{c}$.

2. Бородкин Ф.М., Коряк Н.М. Внимание: конфликт. Новосибирск : Наука, 1989. - 190 с.

3. Генов $Ф$. Психологические особенности мобилизационной готовности спортсмена. - М. : ФиС, 1971. - $241 \mathrm{c}$.

4. Дергач А.А., Зазыкин В.Г. Акмеология: Учебное пособие. - СПб. : Питер, 2003. - 256 с.

5. Капияов А.В., Колесникова Е.И. Методические аспекты использования психометрических тестов в дипломном проектировании // Вестник Самарской гуманитарной академии. Серия «Психология». 2011. - № 2 (10). - C. 107-119.

6. Кашапов М.М. Формирование профессионального творческого мышления: учеб. пособие. - Ярославль : ЯрГУ, 2013. - 136 с.

7. Кашапов М.М., Башкин М.В. Психология конфликтной компетентности: учеб. пособие. - Ярославль : ЯрГУ, 2010. - 128 с.

8. Кашапов М.М., Воскресенский А.М. Связь стратегий поведения в конфликте с индивидуальными особенностями спортсменов // Вестник Ярославского государственного университета им. П.Г. Демидова. Серия: Гуманитарные науки.2013. - № 3 (25). - С. 71-75.

9. Кашапов М.М., Федорова Е.В. Специфика адаптированности профессиональных спортсменов с кри- зисной и адаптивной идентичностью // European Social Science Journal (Европейский журнал социальных наук). - 2015. - Т. 1, № 1. - С. 305-309.

10. Кашапов М.M., Девяткина М.В. Структурные характеристики педагогического мышления тренеров и результативность их деятельности // Вестник Ярославского государственного университета им. П.Г. Демидова. Серия: Гуманитарные науки. 2012. - № 4/1 (22/1). - С. 91-95.

11. Кашапов М.М., Скворияова Ю.В. Творческая деятельность профессионала в контексте когнитивного и метакогнитивного подходов // Ярославский психологический вестник. - 2007. - Вып. 22. C. 53-56.

12. Огородова Т.В., Кашапов М.М., Пошехонова Ю.В. Принятие ответственности как фактор профессионального становления спортсмена // Когнитивноакмеологические основы профессионального становления субъекта. Монография. - Ярославль : ИПК «Индиго». - 2013. - С. 265-272.

13. Огородова T.B. Психология спорта. Психология спорта: учеб. пособие. - Ярославль : ЯрГУ, 2013. $120 \mathrm{c}$.

14. Творческая деятельность профессионала в контексте когнитивного и метакогнитивного подходов / под науч. ред. проф. М.М. Кашапова, доц. Ю.В. Пошехоновой. - Ярославль : ЯрГУ, 2012. $384 \mathrm{c}$. 